\title{
Sketching up new geographies: Open sourcing and curriculum development
}

\author{
William Boyd and David Ellis \\ Southern Cross University, Australia
}

\begin{abstract}
The functionality of web 2.0 technologies has caused academics to rethink their development of teaching and learning methods and approaches. The editable, open access nature of web 2.0 encourages the innovative collaboration of ideas, the creation of equitable visual and tactile learning environments, and opportunity for academics to develop contemporary assessment tasks. In reviewing an example of a teaching tool based on Google SketchUp 3D Warehouse, we have had to consider social and cultural changes required by academics adopting and adapting such technology. In using open source and collaborative knowledge technology there is a risk of work - including the work of students and others - being seen to be plagiarised, and this coming into conflict with established rules of academic behaviour. We conclude that universities must not only be willing to invest in the educational infrastructure to avoid communication, ownership, and authority issues, but, more importantly, be prepared to examine cultural change regarding values and beliefs around ownership of knowledge and the roles of collaborative knowledge generation.
\end{abstract}

\section{Introduction}

"What is clear ... is the ways in which web 2.0 can potentially enhance the learning experience through facilitating group responses, enabling access to external experts ... or by encouraging and supporting networking and the formation of communities of practice. ... The positive results, however, were not universal, and the stories tell of the reluctance of some students to engage beyond their comfort zones, or beyond the boundaries of the task set." (Harris, Warren, Smith, \& Carey, 2011, p. 88).

Drawing on a model of innovation and adoption (Rogers, 2003), we present a short reflective paper recording a conversation about the ways in which web 2.0 could be adopted into university and school teaching and learning potentially enhancing the learning experiences of students. The intent is to consider the required culture changes that might accompany such web 2.0 adoption. While the paper does not focus on empirical research or development of a new pedagogical tool, it presents instructional ideas related to the use of web 2.0 technologies and potential issues surrounding this approach. The purpose is to provide a focus for reflection and discussion of issues around potential contradictions between the use of web 2.0 technologies and traditional educational cultures and pedagogies in higher education (Lim, So, \& Tan, 2010). As such, it focuses explicitly on issues of staff and institutional uptake and engagement, rather than on student engagement per se, with the intention of opening a discussion around the cultural change implicit in transitions from web 1.0 to web 2.0 technology supported pedagogy.

The paper comprises a conversation between two academics, forming a study that is methodologically grounded in the recognition that practitioner self-reflection has a long history as a valid mode of analysis, and thus harnesses the practical application of experiential learning with the strengths of reflection-inaction and reflection-on-action (Chamberlayne, Bornat, \& Wengraf, 2000; Fry, Ketteridge, \& Marshall, 2003; Schön, 1987). In practical terms, one of us is an early career academic engaged in ICT-based pedagogy - an innovator - and the other is an established academic well versed in pre-web 2.0 pedagogy - an early adopter or early majority member. The important point is that by marrying the very different perspectives of early career and established academic experience, we are able to address the tensions inherent in the potential uptake of new technology without being either overly optimistic or overly reactive. Our discussions become a conversation rather than a debate on merits - or otherwise - of new technology. In having such a conversation, we sit at the productive interface of higher education, an interface at which web 2.0 may gain traction within an institution - the university - currently grappling with the tensions of maintaining tradition while embracing innovation and change to cater for a changing technological society. 
The opening quote primarily considered the implications of adopting web 2.0 social networking functions within education. However, these observations are transferrable in the consideration of other web 2.0 functions, and demonstrate that the expanding opportunities of interactive, open source and communicative technologies that web 2.0 functions can bring to education. The study from which it comes usefully reminds academics that new technology may be confronting. Boyd and Newton (2011, p. 8), for example, have recently reflected on the "potential impact of competing interests and shifting loci [of] the growing use of digital technology and on-line teaching and learning environments". In considering curriculum and pedagogical engagement with emerging software and online environment, they highlight both the role of challenges to, and the opportunities to reflect upon, traditional academic and scholarly values through critical engagement with the new functionality. In the study presented here, we highlight the potential tensions between, on the one hand, the open source and collaborative nature of knowledge and its use in some web 2.0 functionality, and, on the other hand, concepts of academic misconduct associated with use, either acknowledged or unacknowledged, of non-original data (otherwise often referred to as plagiarism) (Boyd \& Newton, 2011, in press). We argue that the academy needs to engage a critique of the intellectual culture associated with teaching and learning where new technology poses challenges to cherished beliefs.

Both the tension between the challenges and the reflective opportunities, and the lived experience of any institution engaging in adopting new technology, whether it be web 2.0 or other, mirror the processes of adoption of innovation in any situation (Rogers, 2003). Innovators are a least common group of people, who, as risk takers, pave the way for change. They play an important role in communicating and diffusing new ideas. Early adopters are opinion leaders, willing to try out new ideas. The early majority tend to be careful, thoughtful people who, nevertheless accept change more quickly than the average. The late majority, on the other hand, are typically more cautious, risk averse, adopting or using new ideas only when the majority are already using it. The academy comprises people in all groups, so it may be expected that adoption of new technology - here opportunities that the web 2.0 environment offer - may be variably received, taken up with enthusiasm by some, treated with scepticism (and worse?) by others. What may be liberating for some, will represent an assault on conventional values and behaviours by others. This paper looks at a small case study of such tensions.

Any discussion of adoption and engagement of a new technology or approach in an established set of activities will touch on many aspects of the cultural practices of these activities. It is important, therefore, to remind ourselves that the core issue here is that of potential contradictions between the use of web 2.0 technologies - and the cultural expectations and mores of that use -- and the established practices and implications of traditional cultures and pedagogies in higher education. Noting that web 2.0 is a social and participatory web, Lim et al. (2010) argue that the use of such technology encourages community building and participation, and that, importantly, this differs significantly from previous (web 1.0) online education, where content was generated then delivered for passive consumption. The implication of this shift represents, Lim et al. claim, a new paradigm of higher education, which "presents unique and complex challenges" (p. 205) in the breaking of traditional pedagogical cultures and the creation of virtual spaces that are open for students to interact with. While such challenges may be viewed (by some) to be largely technological, they are better characterised as being a combination of cultural and social as well as technological (Lim et al., 2010; den Exter, Rowe, Boyd, \& Lloyd, 2012; Newell, Pembroke, \& Boyd, 2012).

Lim et al. (2010) suggest a solution to managing the transition from conventional formal pedagogy to the interactive culture of web 2.0, through the development of literacies. For non-web 2.0 practitioners, developing appropriate literacy may seem difficult (Boyd \& Newton, in press). Pedagogically, literacies comprise the activities designed to develop the skills and knowledge in a particular context; if the development of web 2.0 literacies are viewed in this way, the transition may not, Lim et al. contend, be as challenging for educators.

\section{Methodological considerations}

There is a growing literature on what is increasingly being termed "neogeography" (e.g., Haklay, Singleton, \& Parker, 2008; Goodchild, 2009; Hudson-Smith, Crooks, Gibin, Milton, \& Batty, 2009; Graham, 2010), the interface between geolocated activity and web 2.0 technology. Neogeography has been said to be "a way to describe people's activities when using and creating their own maps, geo- 
tagging pictures, movies, websites, etc. ... a new bottom-up approach to geography prompted by users [and] therefore introducing changes in the roles of 'traditional' geographers and 'consumers' of geographical contents themselves" (Beniamino Murgante, personal communication, 2011). While this paper considers a small application within the range of possibilities that neogeography offers, we do not do so to examine neogeography per se, but to think of its implications in introducing web 2.0 pedagogy in higher education. We, therefore, consider this in terms of the emerging geographies of education as real and virtual places, spaces and landscapes - physical, social and cultural - of teaching and learning. Our interest here is in the potential of web 2.0 to redefine the fundamental relationships between teacher, learner, curriculum and pedagogy, and, in other words, maps a new education.

We will demonstrate that, even in considering what some might regard as a relatively benign web 2.0 based teaching tool, we enter a place in this new landscape where we are forced to consider "usurping official authorizing practices in the public domain [and therefore must ask...] fundamental - if not radical - questions for both academic theory and pedagogical practice" (Fountain, n. d.). We do this through a reflective conversation between an early career scholar and an established one, a conversation that helps us shed light on matters of curriculum design and adoption of web 2.0 functions (Boyd, 2011; ElliottJohns, 2011; Searby \& Tripses, 2011). While we start with the consideration of technical aspects, we, perhaps inevitably, find ourselves focusing on some of the social and cultural implications of that design and adoption. In particular, we argue that there is a need for the academy to engage in a critical discussion of emerging practice and belief, rather than a reactive response to the perceived threats of new technology.

\section{A role for web $\mathbf{2 . 0}$ functionality in a university curriculum}

Our conversation was stimulated by an image, downloaded from the 3D Warehouse facility in Google SketchUp, of the Sydney Harbour Bridge (Figure 1) (Google, 2006, 2007). This image was created by an artist/designer/modeller nicknamed 'ilesoft', who has uploaded 125 models (mostly bridges and large commercial buildings) into the 3D Warehouse site. In response to this example, one of us, in familiarising himself with the technology, subsequently developed the Finn House (Figure 2) (Google, 2011a), as an example of the type of exercise that a web 2.0 function could provide for teaching technical design. He did this as part of our mentoring discussions, which he used, with the Harbour Bridge example, to exemplify the ICT issues he was giving thought to in developing a web 2.0 based curriculum in his field of educational technology. In the course of that mentoring conversation, we discussed the context this developing interest in Google SketchUp 3D Warehouse.

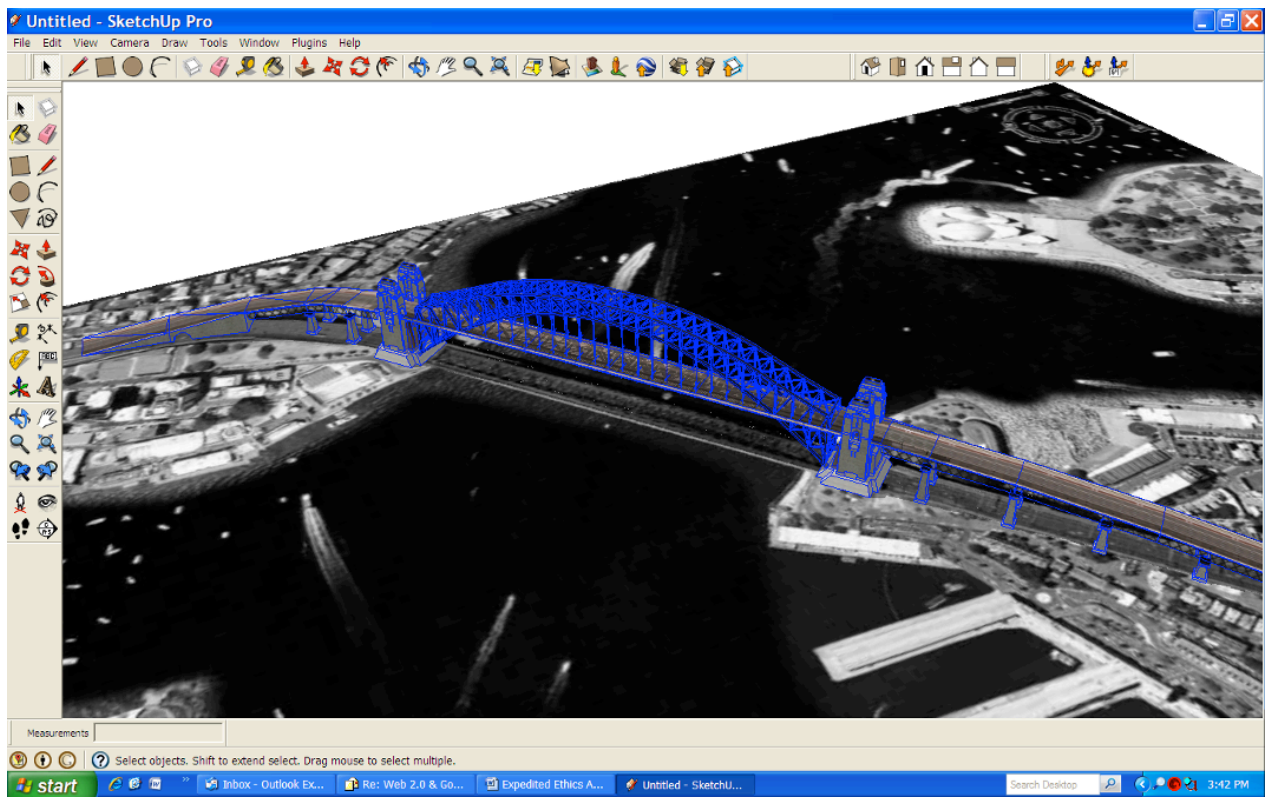

Figure 1. The Sydney Harbour Bridge, drawn by 'ilesoft', is freely available for download in Google SketchUp's 3D Warehouse, as well as being accepted into Google Earth (Google, 2006, 2007). The Harbour Bridge model was the inspiration for our thoughts on interactive activities. 
The Google SketchUp feature, the 3D Warehouse, was evaluated for its potential application for distance education students in our university's Bachelor of Technology Education program. Of particular interest was the way that web 2.0 functionality enables authors or modellers to design and draw a digital 3D model to scale, upload it into the 3D Warehouse, where it becomes free for any Google SketchUp user to evaluate, modify or use as is. From a design perspective, the sharing of information enables authors and other users (in this educational context, student teachers at university, but, in due course, also high school pupils) to collaborate on ideas. It allows them, furthermore, to place these ideas in a virtual geographical context, with the addition of the geographical information program, Google Earth.

Considering the early career scholar's scholarly and teaching interests in the built environment, he explored the possibilities of three potential learning tasks - designed to provide authentic context, that would promote collaboration amongst students and experts, and encourage higher-order thinking skills in the analysis, synthesis and evaluation of virtual models that interact with a simulated world.

The first task would incorporate the use of the Finn House in the 3D Warehouse (Figure 2). The Finn House is based on a real world task, designed and built for a retired couple in the NSW beachside suburb of Moonee Beach in 2010. In consultation with their builder, they developed a house based on their needs as well as the constraints of their building envelope. One appropriate collaborative learning task may ask the students to evaluate the design of the building, this may include the analysis of the site, and to walk around and through the building, evaluating its design according to the needs of the client. The use of walk-through visualisation technology is standard practice in architectural design across the world where designers present solutions to clients. Software features that allow designers to mitigate any potential issues provide a cost benefit, and as a result have become standard features in industry standard software. Furthermore, the ability for designers to be spatially aware and visualise their designs in 3D is not necessarily a skill that the client may possess. As a result, architects use these features to demonstrate how a building or structure will function, using fly-around and walk-through features. The information synthesised during this stage of the learning activity could be presented to the client as a response to the builder's design.

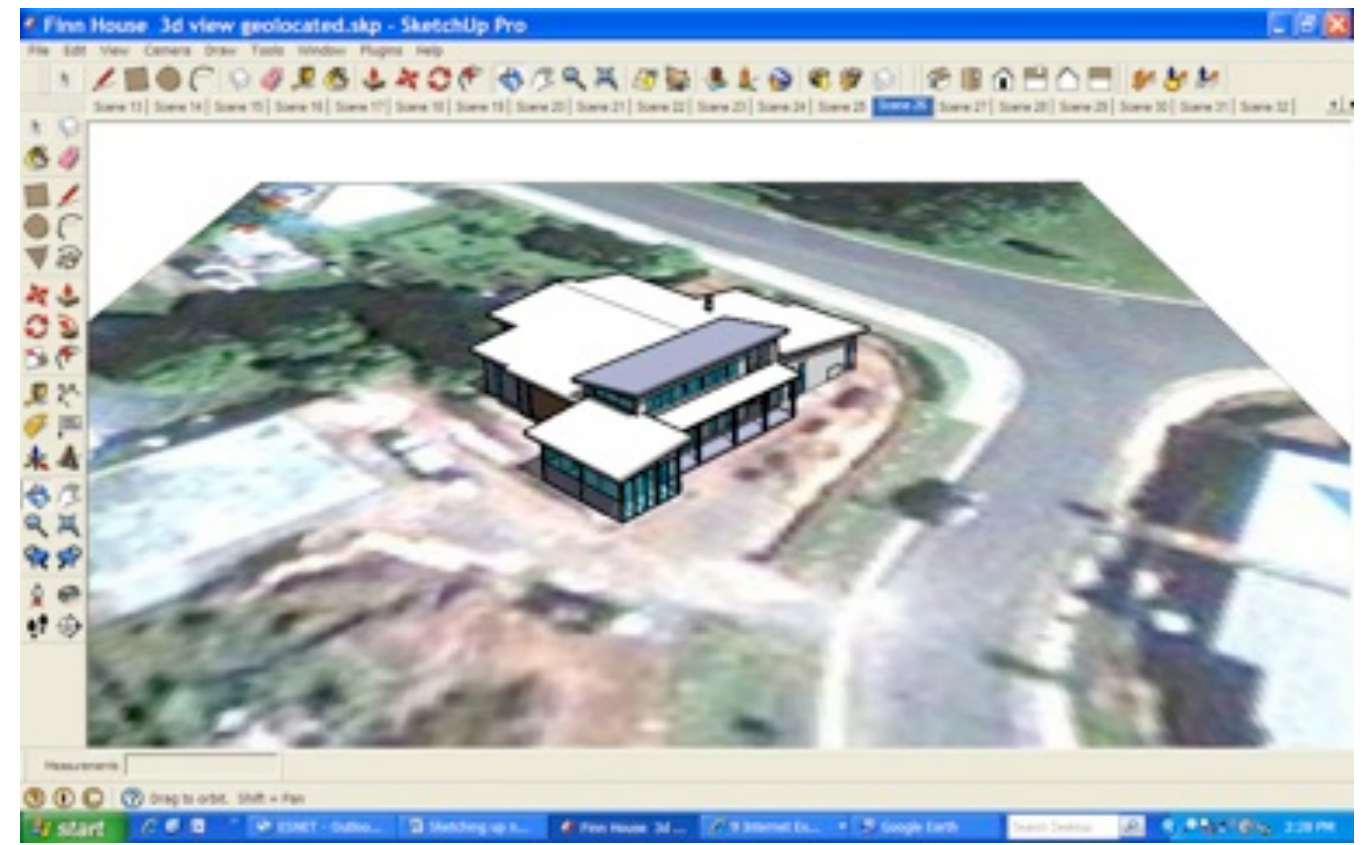

Figure 2. 'Finn House', an exemplar model of a residential house, drawn by one of us, that allows students to assess the building according to pre-determined design criteria (Google, 2011a). 
A second learning task (Figure 2) may require the students to assume the role of the building designer, working directly with the client to determine their needs, taking into consideration the local government authorities development requirements, and the site upon which the Finn House was to be built. The students would demonstrate drawing and design skills as well as the ability to interpret and consider planning documentation in their designs.

The third task (Figure 3) could challenge students to collaborate with planning professionals, and environmental consultants to develop appropriate designs that comply with planning regulations. The local government planning department would designate an appropriate site for development, and the students can respond to these constraints. This site would then undergo analysis (e.g., Figures 4 and 5), and thus be evaluated in terms of its suitability for development as well as any ecological considerations.

The provision of authentic learning experiences is one of the challenges of a distance education degree due to the physical distance between the student, the academic and their interaction with the learning material. The Bachelor of Technology Education degree program at our university requires students to develop both declarative and procedural knowledge within the discipline and access to visual and tactile resources is essential in developing procedural knowledge. A pedagogy that enables all students to experience hands-on tasks, will provide the opportunity for Bloom's higher-order thinking skills. Considering the revised taxonomy, this can be achieved through tasks requiring analysis, synthesis and evaluation in the creation of an equitable learning environment for students, regardless of their physical location (Krathwohl, 2002).

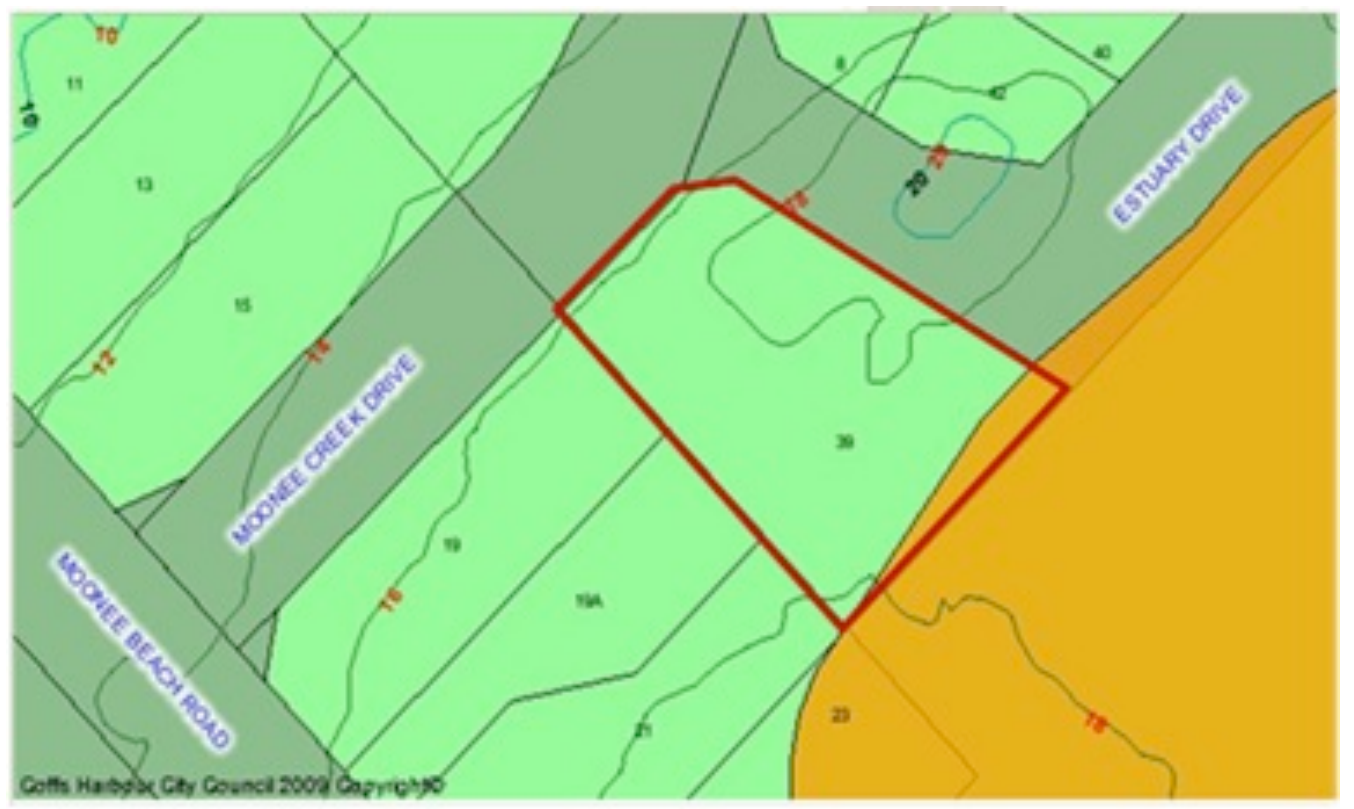

Figure 3. Site for the 'Finn House' (Lot 39). This is a cadastral map accessed freely from the Coffs Harbour City Council's website. This map displays information that could inform a designer about the constraints of a site, such as: existence of acid sulphate soils (light green area); areas that are fire prone (orange area); and the gradient of the site (evidenced by the contours) (Coffs Harbour City Council, 2009). 


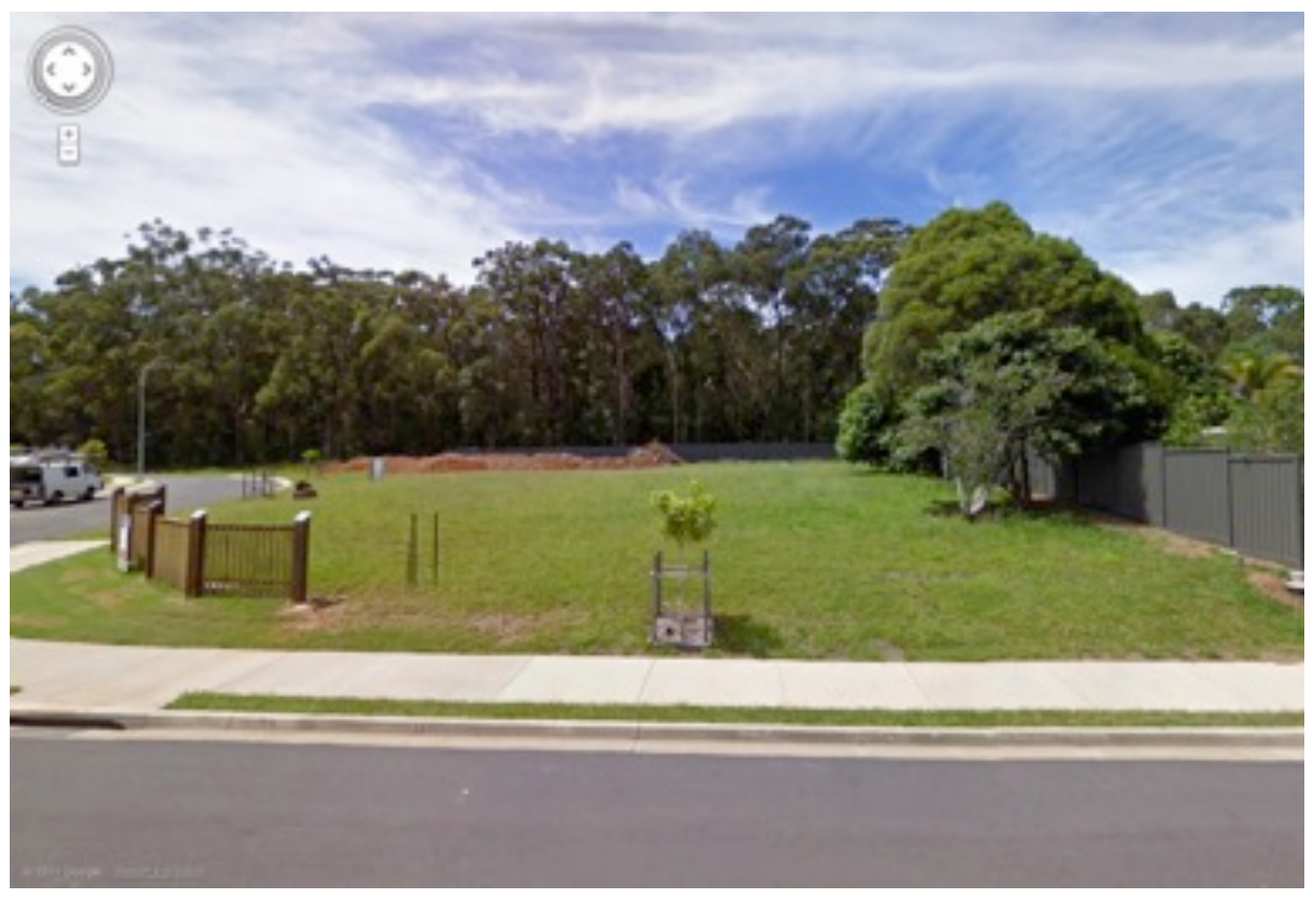

Figure 4. Photographic image of site for the 'Finn House' (Lot 39). Using the 'Street view' feature of Google Maps, designers can: visualise the scale and potential impact of the trees bordering the property; assess the gradient of the site against the contours supplied on the Council's cadastral map (Google, 2011b).

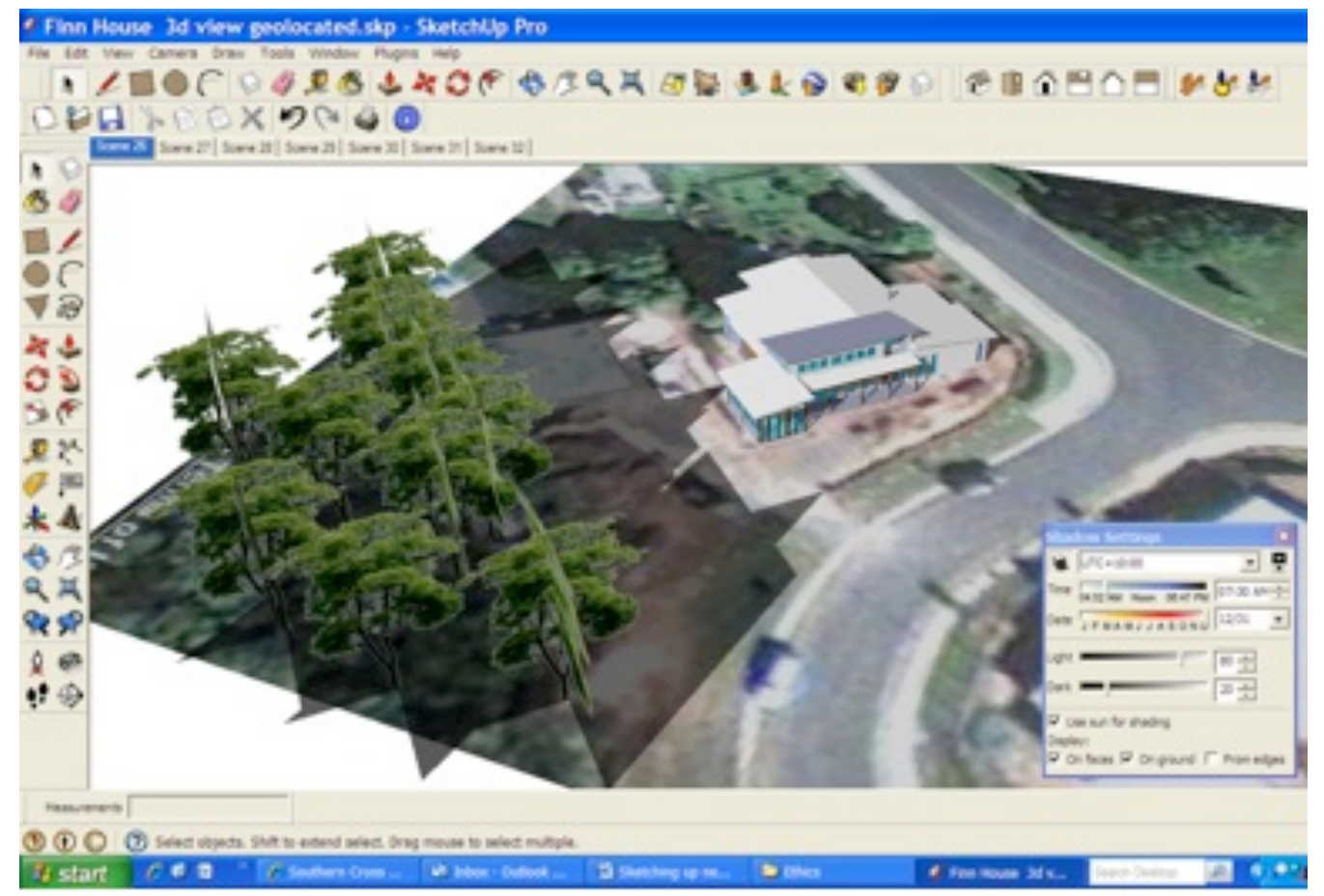

Figure 5. Google SketchUp image of of the Finn House with trees overshadowing the site at 7:30 a.m. in December (Google, 2011c). Designers can assess the best location where the building will be least affected by the overshadowing. 
Importantly, the adoption of a teaching and learning tool such as Google SketchUp 3D Warehouse, and its adaptation to a specific learning context, will depend on the aims and objectives of the learning activities. In our example, asynchronous learning was deemed the most appropriate to a developmental, rather than time-limited, problem solving pedagogy (Hrastinski, 2008). In assessing alternatives to address our teaching and learning needs, however, it should be noted that the synchronous opportunities of virtual world pedagogy with ICT, such as Second Life, did hold some appeal. Having to compare and evaluate such options, and decide which option was most appropriate to our teaching and learning needs, focused our minds on the requirements of our teaching and learning scenario: an ICT pedagogy that enabled students the opportunity to reflect more on complex issues in the built environment. Such reflection requires time, and therefore an asynchronous approach was appropriate. The benefits of an asynchronous learning approach allows the university to consider the life of distance learners outside of an educational context (Compton, Cox, \& Laanan, 2006), providing a continuing platform for developmental group work, and providing opportunity for on-going reflection.

\section{Reflection and discussion}

The images (Figures 1 and 2) were provided in response to a seemingly simple question during our mentoring conversations: "Your geo-design material looks interesting: is there a web 2.0 teaching angle on it?" We now ask ourselves new questions: Could such an interactive and open source facility play a valid pedagogical role in a university curriculum? If so, what issues should we consider? This reflective paper is an immediate response to these questions. In line with the urgency of much web 2.0 functionality, we draw on the vitality of immediate conversation to provide an opening narrative: What role might web 2.0 functionality, such as the Google SketchUp 3D Warehouse, play in teaching and learning? To a large extent, that is described above. We have little doubt that the Google SketchUp 3D Warehouse facility provides a realistic practical frame in which higher-order technical design teaching can be delivered. While we have yet to run this model in a classroom, it is clear that teacher trainers will be the first beneficiaries of this approach, with the expectation that their school students will soon also be using such technology. Den Exter et al. (2012) reach similar conclusions in reviewing slightly more advanced adoption of wikis in higher education teaching and learning. However, there are several other important implications in this proposed approach.

In the context of the school curriculum that our technology education teacher trainers will soon be teaching in schools, there is an interesting challenge to the established culture of teaching. The outcomes of the State's Architectural Drawing module of the (Australian, New South Wales) Graphics Technology syllabus (NSW Board of Studies, 2003, p. 25) require school students (year 10, around 16 years old) to "design ecologically friendly architectural spaces". Conventionally, both the pedagogic approach within schools and the expectations of teachers' skills have focused on the production of architectural standardised working drawings or plans, with only cursory engagement through an ecologicallyconsiderate lens. This issue can be attributed to higher education's unfamiliarity with the concept of ecodesign. One study, for example, found that only $15 \%$ of teaching academics from a design-related discipline had studied sustainable design or ecology to any extent (Ramirez, 2004). Many, indeed, considered themselves self-taught. In the high school context, the reliance of having qualified high school teachers being able to engage with environmental issues is, therefore, compromised where teacher education courses delivered by the higher education sector are dependent on the interests, experience and skills of academic staff. There is a need for the implementation of environmental education in the design education curriculum, to enable "... design educators to become environmental educators" (Barron, Jackson, \& Anderson, 2005, p. 44).

This inequity in teacher training programs with regards to ecological and environmental issues may have a long-term effect. It seems that such a lightly seasoned approach to eco-design has the potential to impede student understanding in the development of richer, ecologically friendly architectural spaces. The incorporation of sustainability issues into the design education curriculum may marginalise sustainability and environmentalism, due to a "shortage of knowledgeable and available design professionals capable/qualified to teach into the programs" (Barron et al., 2005, p. 43).

One approach to improving student learning outcomes is to redirect the source of information from the teacher - as the source of all knowledge - to industry professionals, through consultation and collaboration, in ways that engage participatory learning approaches (Selwyn, 2007) to link students, 
teachers and professionals in discipline relevant contexts. This assists in developing profession-relevant understanding of ecology within the design process, and through simulating problems found in real world situations. Such pedagogy is also known as service-learning (Kenworthy-Uren, 2003), where teaching and learning is founded round the question, "Why not design courses where students actively utilize the tools they learn in our classrooms to address real-world problems today?" Even though much research in this field has focused on actual situations in the community, the virtual environment is also appropriate, considering that students are still attempting to solve real-world problems at the design or planning stages of a project management process, thus being more cost effective. As suggested here, and illustrated above, web 2.0 technology provides an ideal vehicle for this. Engaging consultation between local government, experts and schools can also draw on the social networking strengths of web 2.0 (Harris et al., 2011), thus reducing some of the issues raised earlier regarding the lack of academic engagement with eco-design. This would allow students to use web 2.0 open source, current and accessible technology, and to be immersed in a 3D virtual environment that simulates an actual site, constrained by realistic ecological conditions, and informed by virtually accessible expertise.

Of course, such engagement with web 2.0 social networking and 3D modelling capacities is not without its issues. It presents challenges, for example, to the comfort of students and staff (Harris et al., 2011), or tensions between institutional and pedagogical requirements and cultures (Boyd \& Newton, 2011). At the core of such tensions lie the differences between pre-web 2.0 pedagogy and web 2.0 pedagogy. On the one hand, education has conventionally been dominated by individualistic learning characteristics, albeit mediated through a growing pedagogical interest in teamwork (Boyd \& Newton, in press). On the other hand, the emerging pedagogies attached to web 2.0 technologies, are engaging students in new ways, such as through participatory approaches to learning, and web 2.0 ways of learning (Rollett, Lux, Strohmaier, Dosinger, \& Tochtermann, 2007; Selwyn, 2007). By way of illustration of such tensions, Rollett et al. (2007) discuss the roles of applications and users in web 2.0. Drawing on sources such as Wikipedia and using applications such as Facebook may be practices that are viewed, conventionally, as being inappropriate scholarly practices. They may, alternatively be viewed as providing a valid infrastructure for users to generate, edit, and upload content, within, importantly, specific infrastructure constraints (Rollet et al., 2007). In the case of the 3D warehouse for SketchUp, the name "warehouse" provides an important signal, signifying quite aptly that it is merely a storage facility or a repository; that repository provides users an opportunity for access to information and open sharing of work that they themselves have generated from previously provided material. Such a perspective begs questions of intellectual ownership. In defining the web 2.0 phrase of "some rights reserved", Rollett et al. (2007, p. 92) thus note the importance of understanding intellectual property rights and processes of web 2.0 generated content, especially in relation to how the relaxed rights for this type of content - commonly known as "creative commons" - allows for the remixing of prior resources into new content known as "mash-ups". In practical terms, online providers can redefine the rules of intellectual property. The 3D warehouse facility in Google SketchUp - now being called Trimble SketchUp as this article goes to print - for example, has recently increased its permissions for model sharing where authors can determine whether the models can be viewed publically or privately after an invitation.

While such matters probably underlie educator concerns regarding shifts to web 2.0 pedagogy, they often come to the fore as contestable issues where claims of student integrity are under question (Boyd \& Newton, 2011) - has a student provided his or her original material for assessment? How can the teacher or examiner be assured that the material is original? Where are the boundaries between original and derived results? Such questions, while conventionally addressed as single-issue operational matters (for example, has the student cheated?), actually test the limits of authority and responsibility in the educational setting (Boyd \& Newton, 2011).

In practical terms, the availability of open-source material and web 2.0 functionality specifically raises boundary questions regarding academics' readiness in the assessment of student ICT tasks containing items and material that has been created by other people (i.e., sourced elsewhere) along with their own work. The immediate academic and bureaucratic response is, most frequently, a reactive claim of plagiarism. The discussion that is raised by such a response - or should be - is that of cultural norms and definitions, and of developing new protocols and social expectations and behaviour. More often, however, it is one of resistance and reaction toward the new technology. This need not be. Such resistance and reaction can be considered in the context of inter-generational difference. The current generation of students, those who are regular users of web 2.0 technologies such as Facebook - a generation that 
Selwyn describes as "wiki kids" (2007, p. 1) - are accustomed to working with and creating digital content. The prevalent practice of users building an online profile through social networking sites, for example, blurs the boundaries between virtual and physical relationships (Beer \& Burrows, 2007). This everyday occurrence of convergence in the virtual and physical worlds of users could be considered a natural evolution to incorporate it into more formalised pedagogical activities. They signal shifts in social and cultural norms. The cultural norms around such behaviour this generation are creating include and acknowledge the participatory nature of web 2.0, participation that allows users to sort and reuse existing content in the production of their own, both individual and shared, new content. The implication of such inter-generational difference is that there is the risk of a "digital disconnect" between the lives of these students who rely on, or at least are familiar with and literate in, ICT and web 2.0 functionality in many or all contexts of their everyday lives, and the lives of their teachers and the schools they attend. Why, asks Selwyn (2007, p. 7), should web 2.0 technology not be embraced in schools? And if it is not, do we risk this digital divide posing a "legitimacy crisis"?. Selwyn concludes, therefore, with a warning that dialogue between students and educators needs to occur due to the possibility that educational misappropriation, or worse, of web 2.0 technology will backfire as students react to concerns about esafety, the quality of the learning, and relevance.

The submission of sourced material does not, therefore, mean that the work is necessarily plagiarised, and requires a maturing understanding of the nature of open source material and the cultural norms building around web 2.0 sources and functionality. This particular issue, furthermore, can be addressed easily within conventional structures and practices, adopting and adapting, for example with appropriate referencing and specific marking criteria. There is a need to develop student protocols for appropriate use of the virtual environment, that is, "student protocols to enhance communication online, allowing students the opportunity to "play" and rehearse and experiment with the tools, providing an exemplar and teacher modelling to scaffold learning ..." (Douglas \& Ruyters, 2011, p. 321). Others, in a parallel vein, advise that "the multivoiced and collaborative nature of authorship afforded by wikis, [creates the] need to ensure that assessment protocols consist of both formative and summative components" (Thompson \& Absalom, 2011, p. 375). There needs, therefore, to be a discussion of assessment - and indeed of the whole scholarly activity - based on the use of open source ICT models in student work. How do we assess student work when it has been developed using open source material? If we are going to ignore the open source components of the work, then should it even be there? Or maybe we accept that the use of open source models allows students to design and place models in a simulated environment, and we accept the output, as assessable material, on its own terms, that is as a hybrid-ownership product.

At the practical level, therefore, the proliferation of web 2.0 authoring in student learning activities requires academics themselves to be fully aware in the culture of the technology, so that they can understand the nuances of the different types of authoring tasks and environments: "the interactivity and social interaction that [web 2.0 authoring] encourages cannot be assigned or marked to full effect by using assessment strategies that academics may have used previously, for written reports, essays, examinations or class presentations ..." (Gray, Thompson, Sheard, Clerehan, \& Hamilton, 2010, p. 106). The notion that a cut-and-paste approach to writing an essay is academically wrong simply does not translate into collaborative source learning tasks. The same rules of assessment do not, logically, follow.

There are, of course, other considerations that reinforce this call for a new epistemological approach to teaching and learning. An unexpected issue, for example, is the transparency of web 2.0 technology, while, in considering the vulnerability for wikis and blogs to be vandalised (Gray et al., 2010), university teachers need strategies that can mitigate issues within online learning management systems such as Blackboard. Academics, acting as administrators, can track and view changes to wikis and other forums within such online systems, and even roll back pages to previous versions. Whilst such management seems simple, "monitoring, moderation and administration tasks can be very time-consuming due to the requirement for intensive human resourcing, and may prove to be too great a challenge to ask of educators who already lack time and resources" (Boulos, Maramba, \& Wheeler, 2006). Nevertheless, there is need for practice change.

The implication of these operational reflections and observations is that, while the adoption of a new technology as a pedagogic tool may be straightforward (at least technically), if a bit cumbersome at times, the contextual and cultural ground rules need to be carefully revised and developed. We need to emphasise, for example, the importance of "cultivating the social dynamics ... for creating a safe 
environment for knowledge creation, and thus an important aspect of an innovation ecology" (van Aalst, 2009 , p. 282). Developing the social context will create the conditions for a new engagement between the logic of collaborative or open source technology - Google SketchUp 3D Warehouse, in our case - and the social systems using it - the institution-teacher-learning collective for us (Cress \& Kimmerle, 2008). As others have reminded us, "... the inherently collaborative nature of social web technologies cannot be separated from the complex, ever-evolving and potentially disruptive process of identity formation ...." (Thompson \& Absalom, 2011, p. 382).

We suggest that the same applies to the adoption of collaborative technology such as Google SketchUp's 3D Warehouse. Not only does this technology allow the student to be creative in grounded and authentic ways, but it potentially changes the authority boundaries between the student, teacher and technical design professional. We have alluded already to the boundary issues associated with ownership of assessable material. The implication of this observation is the need for Thomson \& Absolom's (2011) "ever-evolving and potentially disruptive process of identity formation ..." to be harnessed by teachers, curriculum designers and educational governors and managers, as they grapple with the changing conditions of student integrity protocols and rules (Boyd \& Newton, 2011). In other words, there is a need to reconsider academic policy and regulation, in the light of reconsidering fundamental definitions of the social mores and accepted behaviours typical of the academy, a need to action the observation by that "usurping official authorizing practices in the public domain poses fundamental - if not radical questions for both academic theory and pedagogical practice" (Fountain, n. d., p. 1).

In practical terms, this returns to the clarity of definitions of the purpose of learning and assessment activities. In assessing a student's design submission based on the interaction with Google SketchUp 3D Warehouse, are we assessing new and original knowledge or expression of knowledge? Are we, therefore, in some way assessing the student's intellectual grasp of ideas, or are we assessing their engagement with process and understanding of the collaborative nature of knowledge? Or are we simply assessing their technical competence?

\section{Conclusions}

Adoption of web 2.0 technology provides valid and credible pedagogical options in the changing world of networked, global and technological environmental world of the $21^{\text {st }}$ century university (Boyd \& Horta, 2011). Here, we demonstrate a relatively simple way of co-opting collaborative and open source web 2.0 technology - Google SketchUp 3D Warehouse - to address an immediate educational need, the need to provide hands-on experience in eco-design education. In doing this, and potentially engaging the capacity of web 2.0 social networking options, the pedagogical advantage may be enhanced, despite the lack of eco-design background amongst teachers. However, this paper takes this seemingly technical discussion beyond the usual parameters. By adopting a reflective narrative approach in a scholarship of teaching and learning mentoring relationship (Elliott-Johns, 2011), the authors, a technical innovator (mentee) and early adoptor/early majority (mentor) (Rogers, 2003), in seeking to answer a relatively simple mentoring question - interesting looking technology; what is the web 2.0 teaching angle on it? - now understand that the primary issues around the adoption of such web 2.0 technology in teaching are less technical than social. Social issues around the ownership and authorship of knowledge, and therefore the creation of original outputs by students, are challenged by such collaborative and open source technology. The challenge is to our cultural understanding of the ownership and expression of knowledge. The paper ends in supporting other authors calling for the development of appropriate social systems, dynamics and cultures that allow for the acknowledgment and validity of shared knowledge and, thus, shared output generation as valid, honest and unproblematic.

\section{References}

Barron, D., Jackson, S., \& Anderson, L. (2005). Ignorance, environmental education research and design education. Australian Journal of Environmental Education, 21, 39-46.

Beer, D., \& Burrows, R. (2007). Sociology and, of and in Web 2.0: Some initial considerations. Sociological Research Online, 12(5). Retrieved from http://www.socresonline.org.uk/12/5/17.html 
Boulos, M., Maramba, I., \& Wheeler, S. (2006). Wikis, blogs and podcasts: a new generation of Webbased tools for virtual collaborative clinical practice and education. BMC Medical Education, 6(41). Retrieved from http://www.biomedcentral.com/1472-6920/6/41

Boyd, W. E. \& Horta, H. (2011). Network ethics in the growing global, multi-dimensional and technological academy. Introduction to papers presented at the 2009 Network Ethics Conference. International Journal of Cyber Ethics in Education, 1(3), i-v. Retrieved from http://www.informatik.uni-trier.de/ ley/db/journals/ijcee/ijcee1.html

Boyd, W. E., \& Newton, D. (2011). Times of change, times of turbulence: Seeking an ethical framework for curriculum development during critical transition in higher education. International Journal of Cyber Ethics in Education, 1(3), 1-11. Retrieved from http://www.informatik.unitrier.de/ ley/db/journals/ijcee/ijcee1.html

Boyd, W. E., \& Newton, D. (in press). Facilitating the transition into web 2.0 based teaching and learning: Ethical tensions in shifting from individual to communal responsibility in curriculum and pedagogy. International Journal of Cyber Ethics in Education.

Chamberlayne, P., Bornat, J., \& Wengraf, T. (Eds.). (2000). The turn to biographical method in social science. London: Routledge.

Coffs Harbour City Council. (2009). Local Environmental Plan. Retrieved November 23, 2011 from http://maps.coffsharbour.nsw.gov.au/eview-html/index.html

Compton, J. I., Cox, E., \& Laanan, F. S. (2006). Adult learners in transition. New Directions for Student Services, 2006, 73-80. doi:10.1002/ss.208

Cress, U., \& Kimmerle, J.A. (2008). Systemic and cognitive view on collaborative knowledge building with wikis. Computer-Supported Collaborative Learning, 3, 105-122.

den Exter, K., Rowe, S., Boyd, W. \& Lloyd, D. (2012). Using web 2.0 Technologies for Collaborative Learning in Distance Education - Case Studies from an Australian University. Future Internet, 4(1), 216-237; doi:10.3390/fi4010216.

Douglas, K., \& Ruyters, M. (2011). Developing graduate attributes through role-plays and online tools: Use of wikis and blogs for preparation and reflection. In S.-M. Barton, J. Hedberg, \& K. Susuki, (Eds.), Global Learn Asia Pacific 2011 (pp. 316-323). Melbourne: AACE.

Elliott-Johns, S. E. (2011). Reclaiming a writing voice as a new teacher educator: SoTL as portal. International Journal for the Scholarship of Teaching \& Learning, 5(2), 9pp. Retrieved from http://academics.georgiasouthern.edu/ijsotl/v5n2.html

Fountain, R. (n. d.). Wiki pedagogy. Dossier Practiques, Profetic. Retrieved November 23, 2011 from http://www.profetic.org/dossiers/dossier_imprimer.php3?id_rubrique=110

Fry, H., Ketteridge, S., \& Marshall, S. (2003). A handbook for teaching and learning in higher education: Enhancing academic practice. London: Routledge Falmer.

Goodchild, M. (2009). NeoGeography and the nature of geographic expertise. Journal of Location Based Services, 3(2), 82-96.

Google. (2006). Google 3D Warehouse. Retrieved on November 23, 2011 from http://SketchUp.google.com/3dWarehouse/

Google. (2007). ilesoft's bridges > Sydney Harbour Bridge. Retrieved November 29, 2011 from http://SketchUp.google.com/3dWarehouse/details?mid=54655f27c8e9fc9a6adb37c2c15a1a3e 
Google. (2011a). Finn House. Retrieved November 23, 2011 from http://SketchUp.goole.com/3dWarehouse/details?mid=d6f8a00e14313974f1e5f5c0b95849bb

Google. (2011b). Street view. Retrieved November 23, 2011 from http://maps.google.com.au/

Google. (2011c). Finn House 3D view geolocated. Google SketchUp.

Graham, M. (2010). Neogeography and the palimpsets of place: Web 2.0 and the construction of a virtual Earth. Tijdschrift voor Economische en Sociale Geografie, 101(4), 422-436.

Gray, K., Thompson, C., Sheard, J., Clerehan, R., \& Hamilton, M. (2010). Students as Web 2.0 authors: Implications for assessment design and conduct. Australasian Journal of Educational Technology, 26(1), 105-122.

Haklay, M., Singleton, A., \& Parker, C. (2008). Web Mapping 2.0: The neogeography of the GeoWeb. Geography Compass, 2(6), 2011-2039.

Harris, L., Warren, L., Smith, K., \& Carey, C. (2011). Web 2.0: Privacy and integrity in the virtual campus. International Journal of Cyber Ethics in Education, 1(3), 78-91. Retrieved from http://www.informatik.uni-trier.de/ ley/db/journals/ijcee/ijcee1.html

Hrastinski, S. (2008). A study of asynchronous and synchronous e-learning methods discovered that each supports different purposes. EDUCAUSE Quarterly, 31(4), 51-55, Retrieved from http://www.educause.edu/EDUCAUSE+Quarterly/EDUCAUSEQuarterlyMagazineVolum/Asynchron ousandSynchronousELea/163445

Hudson-Smith, A., Crooks, A., Gibin, M., Milton, R., \& Batty, M. (2009). NeoGeography and Web 2.0: concepts, tools and applications. Journal of Location Based Services, 3(2), 118-145.

Kenworthy-Uren, A. (2003). Service-learning and negotiation: Engaging students in real-world projects that make a difference. Negotiation Journal, 19(1), 53-63.

Krathwohl, D. R. A. (2002). Revision of Bloom's taxonomy: An overview. Theory into Practice, 41(4), 212-218.

Lim, W. Y., So, H. J., \& Tan, S. C. (2010). Elearning 2.0 and new literacies: Are social practices lagging behind?. Interactive Learning Environments, 18(3), 203-218.

Newell, D. A., Pembroke, M. M., \& Boyd, W. E. (2012). Crowd sourcing for conservation: Web 2.0 a powerful tool for biologists. Future Internet, 4, 551-562. doi:10.3390/fi4020551

NSW Board of Studies. (2003). Graphics Technology years 7-10 syllabus. Sydney: New South Wales Board of Studies.

Ramirez, M. (2004). Ecological sustainability integration in Australian industrial design education. Paper presented at 2004 FutureGround International Conference of the Design Research Society, Melbourne, Australia.

Rogers, E. M. (2003). Diffusion of innovations. New York: The Free Press.

Rollett, H., Lux, M., Strohmaier, M., Dosinger, G., \& Tochtermann, K. (2007). The Web 2.0 way of learning with technologies. International Journal of Learning Technologies, 3(1), 87-107.

Schön, D. (1987). Educating the reflective practitioner. San Fransisco: Jossey-Bass.

Searby, L. J., \& Tripses, J. S. (2001). Going to the balcony: Two professors reflect and examine their pedagogy. International Journal for the Scholarship of Teaching and Learning, 5(1), 11pp. Retrieved from http://www.georgiasouthern.edu/ijsotl 
Selwyn, N. (2007). Web 2.0 applications as alternative environments for informal learning - a critical review. Paper presented at CERI-KERIS International Expert Meeting on ICT and Educational Performance 16-17 October 2007, Cheju Island, South Korea. Retrieved from http://www.oecd.org/edu/ceri/39458556.pdf.

Thompson, C., \& Absalom, M. (2011). Working with wikis: Collaboration, authorship and assessment in higher education. In S.-M. Barton, J. Hedberg, \& K. Susuki, (Eds.), Global Learn Asia Pacific 2011 (pp.375-384). Melbourne: AACE.

van Aalst, J. (2009). Distinguishing knowledge-sharing, knowledge-construction, and knowledge-creation discourses. Computer-Supported Collaborative Learning, 4, 259-287.

Corresponding author: W. E. Boyd, william.boyd@scu.edu.au

Australasian Journal of Educational Technology (C) 2013.

Please cite as: Boyd, W. E., \& Ellis, D. (2013). Sketching up new geographies: Open sourcing and curriculum development. Australasian Journal of Educational Technology, 29(3), 403-415. 